\title{
Anti-D4GDI antibodies activate platelets in vitro: a possible link with thrombocytopenia in primary antiphospholipid syndrome
}

C. Barbati ${ }^{i^{* \dagger}}$ (D) L. Stefanini ${ }^{1 \dagger}$, T. Colasanti ${ }^{1}$, E. Cipriano ${ }^{1}$, A. Celia ${ }^{1}$, G. Gabriele ${ }^{1}$, M. Vomero ${ }^{1}$, F. Ceccarelli $^{1}$,

F. R. Spinelli ${ }^{1}$, A. Finucci ${ }^{1}$, M. Speziali ${ }^{1}$, G. Orso ${ }^{1}$, D. P. E. Margiotta ${ }^{2}$, F. Conti ${ }^{1}$, F. Violi ${ }^{1}$, A. Afeltra ${ }^{2}$, G. Valesini ${ }^{1}$ and

C. Alessandri ${ }^{\top}$

\begin{abstract}
Background: Thrombocytopenia is a manifestation associated with primary antiphospholipid syndrome (PAPS), and many studies have stressed the leading role played by platelets in the pathogenesis of antiphospholipid syndrome (APS). Platelets are highly specialized cells, and their activation involves a series of rapid rearrangements of the actin cytoskeleton. Recently, we described the presence of autoantibodies against D4GDI (Rho GDP dissociation inhibitor beta, ARHGDIB) in the serum of a large subset of SLE patients, and we observed that anti-D4GDI antibodies activated the cytoskeleton remodeling of lymphocytes by inhibiting D4GDI and allowing the upregulation of Rho GTPases, such as Rac1. Proteomic and transcriptomic studies indicate that D4GDI is very abundant in platelets, and small GTPases of the RHO family are critical regulators of actin dynamics in platelets.

Methods: We enrolled 38 PAPS patients, 15 patients carrying only antiphospholipid antibodies without clinical criteria of APS (aPL carriers) and 20 normal healthy subjects. Sera were stored at $-20^{\circ} \mathrm{C}$ to perform an ELISA test to evaluate the presence of anti-D4GDI antibodies. Then, we purified autoantibodies anti-D4GDI from patient sera. These antibodies were used to conduct in vitro studies on platelet activation.

Results: We identified anti-D4GDI antibodies in sera from 18/38 (47\%) patients with PAPS, in sera from 2/15(13\%) aPL carriers, but in no sera from normal healthy subjects. Our in vitro results showed a significant $30 \%$ increase in the activation of integrin allb $\beta 3$ upon stimulation of platelets from healthy donors preincubated with the antibody anti-D4GDI purified from the serum of APS patients.
\end{abstract}

Conclusions: In conclusion, we show here that antibodies anti-D4GDI are present in the sera of PAPS patients and can prime platelet activation, explaining, at least in part, the pro-thrombotic state and the thrombocytopenia of PAPS patients. These findings may lead to improved diagnosis and treatment of APS.

Keywords: Primary antiphospholipid syndrome, Platelets, D4GDI, Rho GTPases

\footnotetext{
* Correspondence: cristiana.barbati1@gmail.com

${ }^{+} \mathrm{C}$. Barbati and L. Stefanini contributed equally to this work.

${ }^{1}$ Department of Internal Medicine and Medical Specialties, Sapienza

University of Rome, Viale del Policlinico, 155 Rome, Italy

Full list of author information is available at the end of the article
}

(c) The Author(s). 2019 Open Access This article is distributed under the terms of the Creative Commons Attribution 4.0 International License (http://creativecommons.org/licenses/by/4.0/), which permits unrestricted use, distribution, and reproduction in any medium, provided you give appropriate credit to the original author(s) and the source, provide a link to the Creative Commons license, and indicate if changes were made. The Creative Commons Public Domain Dedication waiver (http://creativecommons.org/publicdomain/zero/1.0/) applies to the data made available in this article, unless otherwise stated. 


\section{Background}

Primary antiphospholipid syndrome (PAPS) is a condition characterized by the occurrence of thromboembolic events and/or pregnancy loss combined with presence of circulating anti-phospholipid antibodies (aPLs) [1]. Importantly, the clinical criteria include only thrombosis and pregnancy morbidity; another manifestation associated with antiphospholipid syndrome (APS), but not part of the 2006 Sydney classification criteria to define APS, is thrombocytopenia [2].

Several hypotheses were put forward to explain the causal role of antibodies in the clinical manifestation of APS, and many studies have stressed the leading role played by platelets in the pathogenesis of APS, but none is fully convincing [3]. APS is classified into primary and secondary, the latter being associated with connective tissue disease. Systemic lupus erythematosus (SLE) is the most common cause of secondary APS, and the prevalence of aPLs, either LA or aCL or anti- $\beta 2 \mathrm{GPI}$, in patients with SLE is reported to be as high as $30 \%$ to $50 \%$ [4]. Recently, we described the presence of autoantibodies against D4GDI (Rho GDP dissociation inhibitor beta, ARHGDIB) in the serum of a large subset of SLE patients. Moreover, in the same patients, according to the presence or absence of serum anti-D4GDI Abs, we found a significant association between the presence of these autoantibodies and the evidence of hematologic manifestations (defined as hemolytic anemia with elevated reticulocytes, leucopenia $<4000 / \mathrm{mm}^{3}$ on $\geq 2$ occasions, lymphopenia $<1500 / \mathrm{mm}^{3}$ on $\geq 2$ occasions, thrombocytopenia $<100,000 / \mathrm{mm}^{3}$ ) [5]. D4GDI is a negative regulator of small GTPases of the RHO family, and we observed that anti-D4GDI antibodies activated the cytoskeleton remodeling of lymphocytes by inhibiting D4GDI and allowing the upregulation of Rho GTPases such as Rac1 [5].

Proteomic and transcriptomic studies indicate that D4GDI is very abundant in platelets [6-8]. Platelets are highly specialized cells that once generated by megakaryocytes, patrol the vasculature to ensure its integrity. Their activation involves a series of rapid rearrangements of the actin cytoskeleton, which are crucial for platelet adhesion to vascular lesions and release of bioactive molecules from their granules [9]. Small GTPases of the RHO family are critical regulators of these actin dynamics in platelets [10]. Thus, we hypothesized that autoantibodies anti-D4GDI, if present in the serum of PAPS patients, could promote platelet activation and explain, at least in part, the thrombotic events and the thrombocytopenia.

The aim of the present study was to evaluate the presence of anti-D4GDI antibodies in PAPS sera and whether they can affect platelet activation, contributing to the thrombotic events and the thrombocytopenia of PAPS patients.

\section{Materials and methods}

\section{Patient and control recruitment and ELISA test}

Thirty-eight PAPS patients diagnosed according to the 2006 Sydney classification criteria were enrolled from the Lupus Clinic of the Sapienza University of Rome.15 patients carrying only antiphospholipid antibodies without clinical criteria of APS (aPL carriers) and 20 normal healthy subjects (NHS) served as controls. The local ethic committee approved this study (Prot n 154/19), and participants gave their written informed consent. Sera were stored at $-20^{\circ} \mathrm{C}$ to performed an ELISA test using commercial D4GDI protein.

\section{Purification of specific autoantibodies from patient sera}

Recombinant D4GDI $(50 \mu \mathrm{g})$ was spotted onto a nitrocellulose filter and incubated with sera from APS patients that had OD $>0.86$ by ELISA. The antibodies were eluted with $100 \mathrm{mM}$ glycine, $\mathrm{pH} 2.5$, immediately neutralized with $1 \mathrm{M}$ Tris $\mathrm{HCl}, \mathrm{pH} 8$, and dialyzed against PBS.

To exclude variations in binding reactivity after the purification process, purified anti-D4GDI antibodies were tested by ELISA [5].

\section{Platelet preparation and in vitro activation}

Venous blood was drawn in trisodium citrate $(3.8 \%, 1 / 10$ $(v: v))$ from NHS $(n=5)$ who had fasted for at least $12 \mathrm{~h}$. To wash platelets, blood was immediately centrifuged for $15 \mathrm{~min}$ at $180 \mathrm{~g}$ at room temperature, and platelet-rich plasma (PRP) was separated. To avoid leukocyte contamination, only the top $75 \%$ of the PRP was collected. PRP was centrifuged twice in the presence of prostaglandin $\mathrm{I}_{2}$ for $10 \mathrm{~min}$ at $300 \mathrm{~g}$ and resuspended in Tyrode's buffer containing mmol/L (137 NaCl, $0.3 \mathrm{Na}_{2} \mathrm{HPO}_{4}, 2 \mathrm{KCl}, 12$ $\mathrm{NaHCO}_{3}, 5 \mathrm{~N}$-2-hydroxyethylpiperazine-N'-2-ethanesulfonic acid, 5 glucose) pH 7.3 containing $0.35 \%$ BSA (fraction V, Sigma-Aldrich) to a final concentration of $10^{8}$ platelets $/ \mathrm{ml}$. Washed platelets were then incubated at $37^{\circ} \mathrm{C}$ with $20 \mu \mathrm{g} / \mathrm{ml}$ of the purified antibody anti-D4GDI or with the same volume of buffer (PBS).

For determination of integrin $\alpha \operatorname{IIb} \beta 3$ activation, a wellestablished marker of platelet activation and adhesion, $20 \mu \mathrm{l}$ of pre-treated platelets was stimulated with adenosine diphosphate (ADP, $10 \mu \mathrm{M}$; Sigma-Aldrich, Saint Louis, USA) or not (no stimulation) for $10 \mathrm{~min}$ in the presence of $1 \mathrm{mM} \mathrm{CaCl} 2$ and $5 \mu \mathrm{g} / \mathrm{ml} \mathrm{PAC1-FITC} \mathrm{(BD}$ Biosciences, cat \# 340507), an antibody directed towards the activated form of human $\alpha \operatorname{IIb} \beta 3$ [11]. Following stimulation, the samples were diluted with $1 \mathrm{ml}$ of PBS and analyzed immediately with a BD Accuri ${ }^{\mathrm{Tm}}$ C6 Plus flow cytometer. Data is shown as \% of control, considering the mean fluorescence intensity of the activated control as $100 \%$ (mean $\pm \mathrm{SD})$.

For determination of integrin $\alpha \operatorname{IIb} \beta 3$ activation in real time, washed platelets pre-treated with $20 \mu \mathrm{g} / \mathrm{ml}$ 
of anti-D4GDI or buffer were further diluted to $5 \times 10^{6}$ platelets $/ \mathrm{ml}$. After establishing a baseline with unlabeled platelets, $5 \mu \mathrm{g} / \mathrm{ml}$ PAC1-FITC and $25 \mu \mathrm{M}$ ADP were added simultaneously in an equal volume of modified Tyrode's buffer to allow efficient mixing. PAC1-FITC binding was recorded continuously for $150 \mathrm{~s}$ with a BD Accuri $^{\text {mo }}$ C6 Plus flow cytometer [12].

\section{Statistical analysis}

Normal distribution of variables was assessed using the Kolmogorov-Smirnov test. Statistical analysis was performed using the program GraphPad Prism Version 6 (GraphPad Software, San Diego, CA, USA). The MannWhitney unpaired test or Student's $T$ test were used to compare quantitative variables in different groups. Statistical correlation was examined using Spearman's rank correlation coefficient. Values of $p<0.05$ were considered statistically significant.

\section{Results}

Identification of anti-D4GDI antibodies in patients' sera and association with thrombocytopenia

We identified anti-D4GDI antibodies in sera from $18 / 38$ (47\%) patients with PAPS, in sera from $2 / 15$ (13\%) aPL carriers, but in no sera from normal healthy subjects (Fig. 1a). Dividing the patients with APS according to the presence or absence of thrombocytopenia, we found a significant association between this hematologic manifestation and a higher titer of anti-D4GDI antibodies (Fig. 1b). There was no significant correlation with other clinical features and presence of aPLs antibodies (data not shown).

\section{Role of anti-D4GDI antibodies in platelet activation}

Thrombocytopenia can be due to reduced platelet production at the level of megakaryocytes or to increased platelet consumption. We hypothesize that the antibody antiD4GDI has a priming effect on the activation of platelets and thereby contributes to the thrombocytopenia by increasing the consumption of activated platelets that freely circulate in the bloodstream. To test our hypothesis, we measured integrin $\alpha \operatorname{IIb} \beta 3$ activation in basal and ADP stimulated conditions in the presence or absence of antiD4GDI. Our results show (Fig. 2 panel a) a significant 30\% increase in the activation of integrin $\alpha \operatorname{IIb} \beta 3$ upon stimulation of platelets from healthy donors preincubated with the antibody anti-D4GDI purified from the serum of APS patients. The activating effect of the antibody is also detectable in basal (non-stimulated) conditions, but it is not statistically significant. Interestingly the antibody does not only increase the overall integrin activation but also the rate/speed of integrin activation (panel b). These results suggest that the presence of the antibody anti-D4GDI in circulation primes platelets for activation and promotes their rapid switch from an anti-adhesive to a pro-adhesive state when other stimuli, such as ADP leaking from red blood cells, are present.

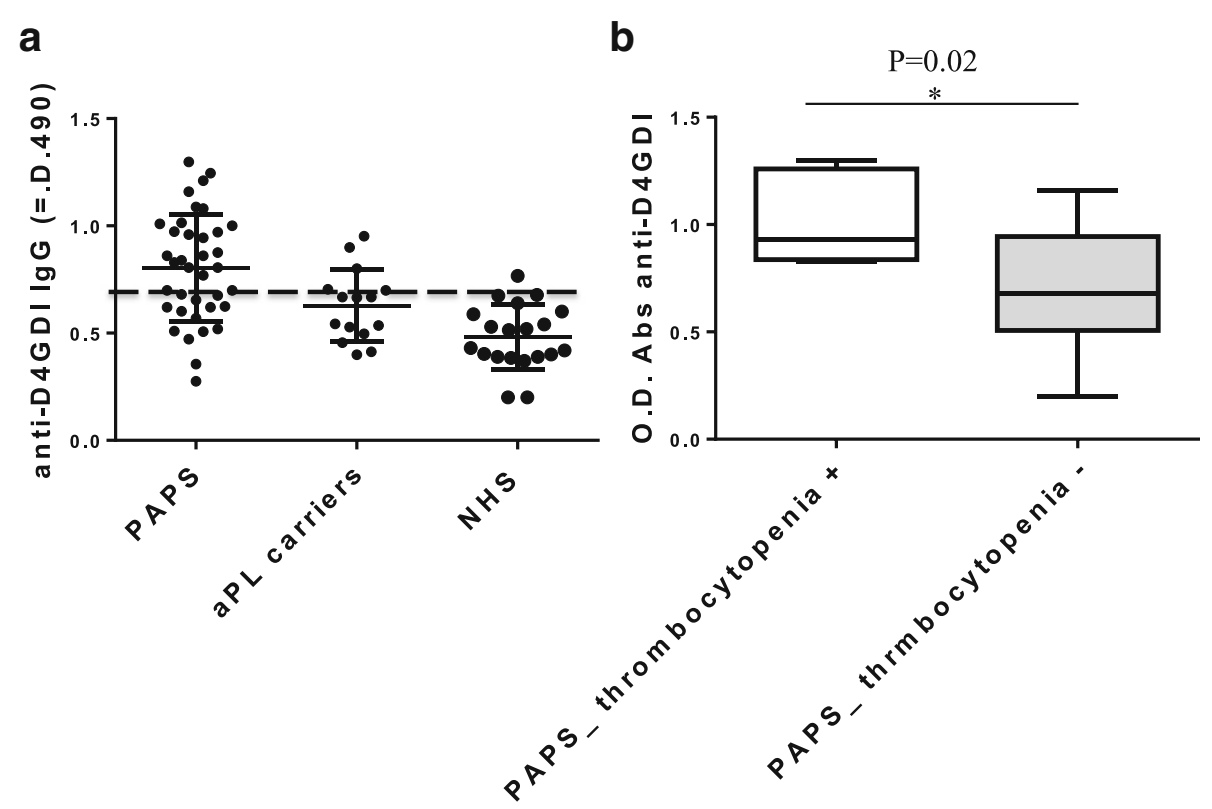

Fig. 1 Evaluation of the specific antibody titer for D4GDI in sera from PAPS patients and normal healthy donors and association of anti-D4GDI antibody titer and thrombocytopenia in PAPS patients. a The image shows the cut-off calculated on normal healthy donors $(\mathrm{OD} 490=0.86) ; 18$ PAPS patients out of $38(47 \%)$ have values higher than the cut-off and therefore considered positive. Only 2 aPL carriers out of 15 have values higher than the cut-off. $\mathbf{b}$ The boxes show how PAPS patients with thrombocytopenia have a higher serum titer of anti-D4GDI antibodies 
a

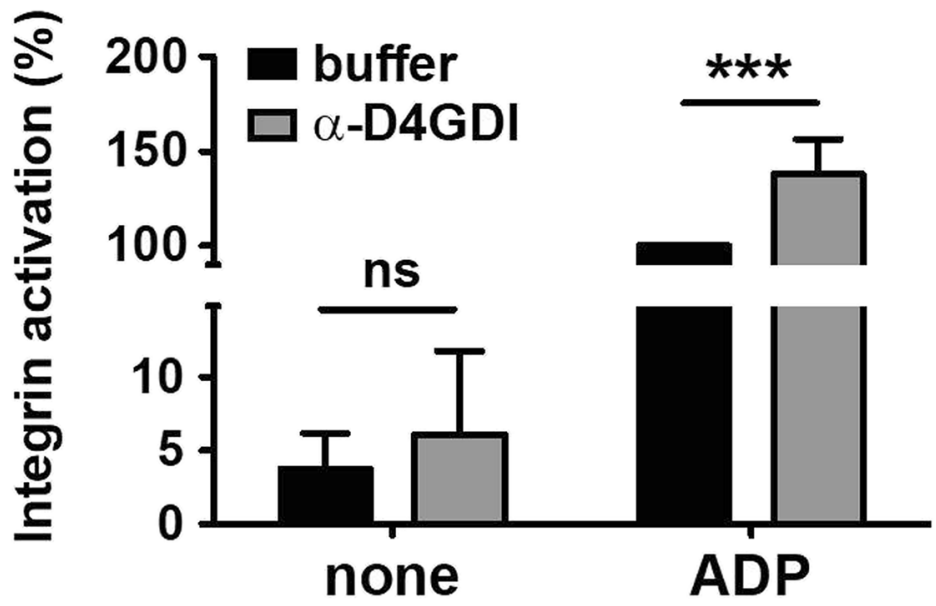

b

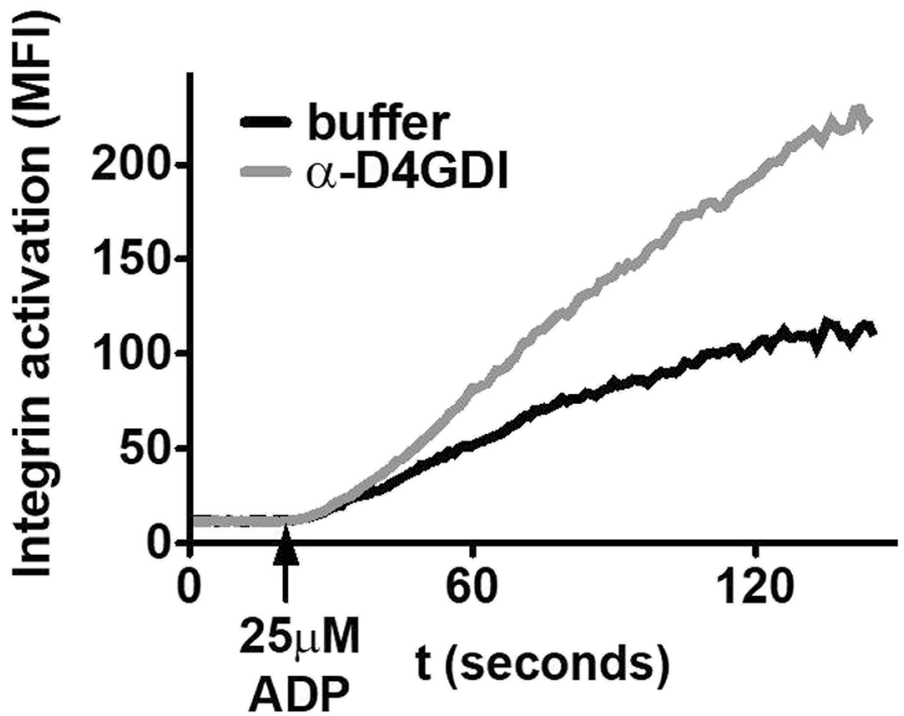

Fig. 2 Platelet activation in the presence of anti-D4GDI antibodies from the sera of PAPS patients. Preincubation of platelets from healthy donors with $20 \mathrm{\mu g} / \mathrm{ml}$ of anti-D4GDI antibodies, purified from the sera of PAPS patients, significantly increases the a total \% $(n=5)$ and the $\mathbf{b}$ kinetic rate (representative image, $n=5$ ) of adenosine diphosphate (ADP)-induced integrin activation (gray line and bar), compared to controls with buffer only (black line and bar). In the absence of agonist stimulation (none), there is a similar trend but is not statistically significant

\section{Discussion}

The main findings of this study are (1) that we detect antiD4GDI antibodies in $47 \%$ of PAPS patients, (2) that a higher titer of anti-D4GDI antibodies is significantly associated with thrombocytopenia, and that (3) the antibodies anti-D4GDI isolated from the serum of APS patients promote agonist-induced platelet activation in vitro.

D4GDI belongs to the family of RhoGDI or GDPdissociation inhibitors for the Rho/Rac family of small $\mathrm{G}$ proteins $[10,11]$. Like other $\mathrm{G}$ proteins, RHO GTPases cycle between an inactive GDP-bound form and an active GTP-form. GDP-dissociation inhibitors stabilize the GDP-bound form thus inhibiting RHOGTPase function. It is well known that D4GDI is highly expressed in hematopoietic tissues. However, the intracellular regulatory function of D4GDI is still poorly understood. The only known fact is that D4GDI, like several other surface molecules [12], is embedded into lipid rafts, subdomains of the plasma membrane that provide a scaffold for signal transduction proteins. In our previous study, we characterized D4GDI as a peripheral blood lymphocyte antigen recognized by serum autoantibodies from a $46 \%$ of patients with SLE [5]. The presence of these autoantibodies appeared associated with (i) increased levels of active (GTPbound) Rac1 and Rho small GTPases and (ii) increased Rho GTPases functional responses, i.e., actin filament polymerization, in lymphocytes [5]. 
Recent proteomic and transcriptomic studies indicate that D4GDI is highly expressed in platelets [6-8]. Consistently with the inhibitory role of D4GDI and with our previous observations in lymphocytes, when we incubate platelets of healthy donors with anti-D4GDI antibodies, we observe an increase in the rate and overall activation of integrin $\alpha \operatorname{IIb} \beta 3$, the integrin that supports plateletplatelet aggregation [9]. Thus, it is plausible that this antibody contributes to the pro-thrombotic state of PAPS patients. Since the effect of anti-D4GDI antibodies on platelet activation is statistically significant upon agonist stimulation but not in resting non-stimulated conditions, we presume that these antibodies do not have a direct stimulatory effect but only a priming effect by releasing one of the brakes that keep platelets inactive in circulation. Thus, allowing their rapid switch from an anti-adhesive to a pro-adhesive state when other stimuli, such as ADP leaking from red blood cells, are present.

Thrombocytopenia is the most common hematological feature of patients with antiphospholipid syndrome [2], and we show here an association between the presence of anti-D4GDI antibodies and low platelet count. Thrombocytopenia can be due to reduced platelet production at the level of megakaryocytes or to increased platelet consumption. Since anti-D4GDI primes platelet activation in vitro and PAPS are by definition pro-thrombotic, we believe that the low platelet count is mainly due to an increased clearance of platelets that are circulating in a pre-activated state. However, since RHO GTPases are also important for megakaryocyte function and pro-platelet release, we may not exclude that the anti-D4GDI antibodies also affect platelet production in the bone marrow.

\section{Conclusions}

In conclusion, we show here that antibodies anti-D4GDI are present in the sera of PAPS patients and can prime platelet activation, explaining, at least in part, the prothrombotic state and the thrombocytopenia of PAPS patients. These findings may lead to improved diagnosis and treatment of APS.

\section{Abbreviations}

aPLs: Anti-phospholipid antibodies; D4GDI: Rho GDP dissociation inhibitor beta; NHS: Normal healthy subjects; PAPS: Primary antiphospholipid syndrome; PRP: Platelet-rich plasma; SLE: Systemic lupus erythematosus

\section{Acknowledgements}

None.

Disclosures

None.

\section{Authors' contributions}

$C B, L S$, and CA collected the clinical data, examined and interpreted the data, performed statistical analyses, and wrote and revised the manuscript. FCe, AF, SM, FRS, CA, and ST recruited patients. CB, TC, MV, and GG carried out the laboratory experiments. CF, VF, and VG revised the manuscript. CE collected the clinical data. CA, FCo, and GV designed, coordinated, and supervised the study and wrote and revised the manuscript. All authors read and approved the final manuscript.

\section{Funding}

None

Availability of data and materials

Datasets analyzed during the current study are available from the corresponding author on reasonable request.

Ethics approval and consent to participate

The protocol of study was approved by the Ethics Committee of Sapienza University of Rome (Prot n 154/19), and informed written consent was obtained from all patients prior to enrollment.

Consent for publication

Not applicable.

\section{Competing interests}

The authors declare that they have no competing interests.

\section{Author details}

${ }^{1}$ Department of Internal Medicine and Medical Specialties, Sapienza University of Rome, Viale del Policlinico, 155 Rome, Italy. ${ }^{2}$ Department of Immuno-Rheumatology, Campus Bio-Medico, University of Rome, Rome, Italy.

Received: 3 May 2019 Accepted: 17 June 2019

Published online: 01 July 2019

References

1. Wilson WA, Gharavi AE, Piette JC. International classification criteria for antiphospholipid syndrome: synopsis of a post-conference workshop held at the Ninth International (Tours) aPL Symposium. Lupus. 2001;10:457-60.

2. Radin M, Ugolini-Lopes MR, Sciascia S, Andrade D. Extra-criteria manifestations of antiphospholipid syndrome: risk assessment and management. Semin Arthritis Rheum. 2018:48:117-20.

3. Shechter Y, Tal Y, Greenberg A, Brenner B. Platelet activation in patients with antiphospholipid syndrome. Blood Coagul Fibrinolysis. 1998;9:653-7.

4. McClain MT, Arbuckle MR, Heinlen LD, Dennis GJ, Roebuck J, Rubertone MV et al. The prevalence, onset, and clinical significance of antiphospholipid antibodies prior to diagnosis of systemic lupus erythematosus. Arthritis Rheum. 2004;50:1226-32.

5. Barbati C, Alessandri C, Vomero M, Vona R, Colasanti T, Vacirca D, et al. Autoantibodies specific to D4GDI modulate Rho GTPase mediated cytoskeleton remodeling and induce autophagy in T lymphocytes. J Autoimmun. 2015;58:78-89.

6. Rowley JW, Oler AJ, Tolley ND, Hunter BN, Low EN, Nix DA, et al. Genomewide RNA-seq analysis of human and mouse platelet transcriptomes. Blood. 2011;118:e101-11.

7. Burkhart JM, Vaudel M, Gambaryan S, Radau S, Walter U, Martens L, et al. The first comprehensive and quantitative analysis of human platelet protein composition allows the comparative analysis of structural and functional pathways. Blood. 2012;120:e73-82.

8. Simon LM, Edelstein LC, Nagalla S, Woodley AB, Chen ES, Kong X, et al. Human platelet microRNA-m- RNA networks associated with age and gender revealed by integrated plateletomics. Blood. 2014;123:e37-45.

9. Yun SH, Sim EH, Goh RY, Park Jl, Han JY. Platelet activation: the mechanisms and potential biomarkers. Biomed Res Int. 2016;2016:9060143 Review.

10. Aslan JE. Platelet Rho GTPase regulation in physiology and disease. Platelets. 2019:30:17-22.

11. Bergmeier W, Schulte V, Brockhoff G, Bier U, Zirngibl H, Nieswandt B. Flow cytometric detection of activated mouse integrin allb $\beta 3$ with a novel monoclonal antibody. Cytometry. 2002;48:80-6.

12. Stefanini $L$, Ye F, Snider AK, Sarabakhsh $K$, Piatt $R$, et al. A talin mutant that impairs talin-integrin binding in platelets decelerates allbß3 activation without pathological bleeding. Blood. 2014;123:2722-31.

\section{Publisher's Note}

Springer Nature remains neutral with regard to jurisdictional claims in published maps and institutional affiliations. 